\title{
Article \\ ZnO Nanoparticles with Controllable Ce Content for Efficient Photocatalytic Degradation of MB Synthesized by the Polyol Method
}

\author{
Gregorio Flores-Carrasco ${ }^{1,2, * \mathbb{D}}$, Micaela Rodríguez-Peña ${ }^{3}$, Ana Urbieta ${ }^{3, * \mathbb{D}}$, Paloma Fernández ${ }^{3}$ (D) \\ and María Eugenia Rabanal ${ }^{2} \mathbb{D}$
}

check for updates

Citation: Flores-Carrasco, G.; Rodríguez-Peña, M.; Urbieta, A.; Fernández, P.; Rabanal, M.E. ZnO Nanoparticles with Controllable Ce Content for Efficient Photocatalytic Degradation of MB Synthesized by the Polyol Method. Catalysts 2021, 11, 71. https://doi.org/10.3390/ catal11010071

Received: 16 December 2020 Accepted: 31 December 2020 Published: 6 January 2021

Publisher's Note: MDPI stays neutral with regard to jurisdictional clai$\mathrm{ms}$ in published maps and institutional affiliations.

Copyright: (C) 2021 by the authors. Licensee MDPI, Basel, Switzerland. This article is an open access article distributed under the terms and conditions of the Creative Commons Attribution (CC BY) license (https:// creativecommons.org/licenses/by/ $4.0 /)$.
1 Higher Technological Institute of Tepeaca, National Technological Institute of Mexico, Tepeaca 75219, Mexico 2 Department of Materials Science and Engineering and Chemical Engineering, University Carlos III of Madrid and IAAB, Avenida de la Universidad 30, 28911 Madrid, Spain; eugenia@ing.uc3m.es

3 Departamento de Física de Materiales, Facultad de Físicas, Universidad Complutense, 28040 Madrid, Spain; micaelar@ucm.es (M.R.-P.); arana@fis.ucm.es (P.F.)

* Correspondence: flcagr@hotmail.com (G.F.-C.); anaur@ucm.es (A.U.)

\begin{abstract}
This paper reports on the synthesis of Ce-doped $\mathrm{ZnO}(\mathrm{CZO})$ nanoparticles (NPs) by an alternative polyol method at low temperature. The method, facile and rapid, uses acetate-based precursors, ethylene glycol as solvent, and polyvinylpyrrolidone as capping agent. The effects of the Ce-doping concentration (ranging from 0 to 8.24 atomic\%) on the structural, morphological, compositional, optical, luminescence, and photocatalytic properties of the NPs were investigated by several techniques. The structural findings confirmed that the CZO NPs have a typical hexagonal wurtzite-type structure with a preferred orientation along the (101) plane. The results obtained by Field Emission Scanning Electron Microscopy (FESEM) and Transmission Electron Microscopy (TEM) revealed that the NPs size decreased (from $\sim 30$ to $\sim 16 \mathrm{~nm}$ ) with an increase in the Ce-doping concentration. Energy Dispersive X-Ray Spectroscopy (EDS) and High Resolution Transmission Microscopy (HRTEM) results confirmed the incorporation of Ce ions into the ZnO lattice. Ce-doping influences the photoluminescence (PL) emission compared to that of pure $\mathrm{ZnO}$. The PL emission is related to the presence of different kinds of defects, which could take part in charge transfer and/or trapping mechanisms, hence playing an essential role in the photocatalytic activity (PCA). In fact, in this work we report an enhancement of PCA as a consequence of Ce-doping. In this sense, the best results were obtained for samples doped with 3.24 atomic $\%$, that exhibited a photocatalytic degradation efficiency close to $99 \%$ after 60 min ultraviolet (UV) illumination, thus confirming the viability of Ce-doping for environmental applications.
\end{abstract}

Keywords: Ce-doped ZnO; nanoparticles; optical properties; photocatalytic activity

\section{Introduction}

In recent years, considerable attention has been paid to the eradication of hazardous substances from wastewater, especially organic pollutants. The photocatalytic reaction has been explored and has turned out to be a desirable method to degrade pollutants in an environmental and economical way [1-3].

Semiconductor materials including $\mathrm{ZnO}$ [1], $\mathrm{TiO}_{2}$ [2], $\mathrm{Nb}_{2} \mathrm{O}_{5}$ [4], $\mathrm{WO}_{3}$ [5], $\mathrm{Bi}_{2} \mathrm{O}_{3}$ [6], are promising candidates for appropriate photocatalysts to decompose organic pollutants. Among them, $\mathrm{ZnO}$ is a significant semiconductor photocatalyst owing to its wide direct band gap $(3.37 \mathrm{eV})$ with large exciton binding energy of $60 \mathrm{meV}$ at room temperature (RT) [1]. Although the $\mathrm{ZnO}$ system presents two crystalline structures, the hexagonal wurtzite and the cubic zinc blende, the wurtzite is by far the most stable structure and hence the most frequently found. Due to its unique properties, such as high chemical and mechanical stability, excellent optical and electrical response, excellent eco-friendly 
behavior, low-cost synthesis, and abundance in nature, $\mathrm{ZnO}$ based photocatalysts have been extensively studied [1,3,7]. So far, numerous efforts have been realized to improve the photocatalytic activity of $\mathrm{ZnO}$ by adjusting the particle size, morphology, orientation, optoelectronic properties as well as other means $[1,8,9]$.

However, the low quantum efficiency yield and the low sensitivity to visible light limit their practical application at present. To overcome these limitations, doping with rare-earth (RE) ions is an effective way to modify the photocatalytic performance of metal oxide semiconductor materials. The RE ions with a $4 \mathrm{f}$ electron configuration are known for their ability to trap electrons, which can effectively decrease the recombination rate of photogenerated electron-hole pairs mainly involved in the reactions leading to the elimination of organic pollutants in wastewater. Generally, these dopants $\left(\mathrm{La}^{3+}, \mathrm{Eu}^{3+}\right.$, $\mathrm{Gd}^{3+}, \mathrm{Dy}^{3+}, \mathrm{Ho}^{3+}$, and $\mathrm{Ce}^{3+}$ ) are introduced into the $\mathrm{ZnO}$ matrix, occupying substitution or interstitial sites $[10,11]$. Among them, Ce seems to be one of the most suitable candidates for enhancing the photocatalytic properties of the $\mathrm{ZnO}$ system [12-16].

Such prospects have led to extensive studies of many aspects of Ce-doped $\mathrm{ZnO}$ $(\mathrm{CZO})$, motivated by the interest in generating new and unique technologies for manufacturing high-quality doped nanomaterials to obtain enhanced catalysts. Due to the attractive properties and potential applications of CZO nanoparticles (NPs), a variety of preparation techniques have been reported, notable examples include, the electrospinning method [12], sonochemical synthesis [13], microwave-assisted synthesis [14], the combustion method [15], the vapor-solid method [16], the sol-gel method [17-19], the magnetron sputtering method [20], and many others [21-24]. However, most of the reported methods are time-consuming, require complicated equipment with expensive chemical precursors, and operate only under particular and controlled reaction conditions such as $\mathrm{pH}$, growth time, concentration, atmosphere, etc. Thus, additional effort is still needed to develop a convenient, cheap and effective method to synthesize lanthanide-doped $\mathrm{ZnO}$ nanomaterials with the best crystal quality attainable. Compared with other reported methods, the polyol-mediated process is easy to perform and requires neither multi-sequential steps nor sophisticated equipment $[25,26]$.

In this work, we present a unique polyol-mediated synthesis method to prepare CZO NPs with different doping concentrations. The effects of doping concentration on the structural, morphological, compositional, optical, luminescent, and photocatalytic properties are investigated in detail.

\section{Results and Discussion}

Several samples with increasing Ce content, nominally ranging from 0.62 to 8.24 at $\%$ were investigated. Figure 1a shows the XRD patterns of the synthesized pure $\mathrm{ZnO}$ and $\mathrm{Ce}$-doped $\mathrm{ZnO}(\mathrm{CZO})$ samples. It can be seen that the $\mathrm{ZnO}$ hexagonal wurtzite-type lattice structure (space group P63mc of dihexagonal pyramidal class, Joint Committee on Powder Diffraction Standards, JCPDS Card no. 89-1397) is the only identified phase in all the CZO samples with different doping contents. This may indicate that the crystal structure has not changed with the incorporation of $\mathrm{Ce}$ in the samples, suggesting that $\mathrm{Ce}$ ions have been uniformly substituted into the crystal lattice of the $\mathrm{ZnO}$ host. For the three most heavily doped samples a very broad and weak bump can be observed for angles below $30^{\circ}$ that could correspond to the diffraction peak reported by Cerrato et al. and associated to $\mathrm{CeO}_{2}[27,28]$. Figure $1 \mathrm{~b}$ shows a zoom of the three more intense peaks in the XRD patterns. 

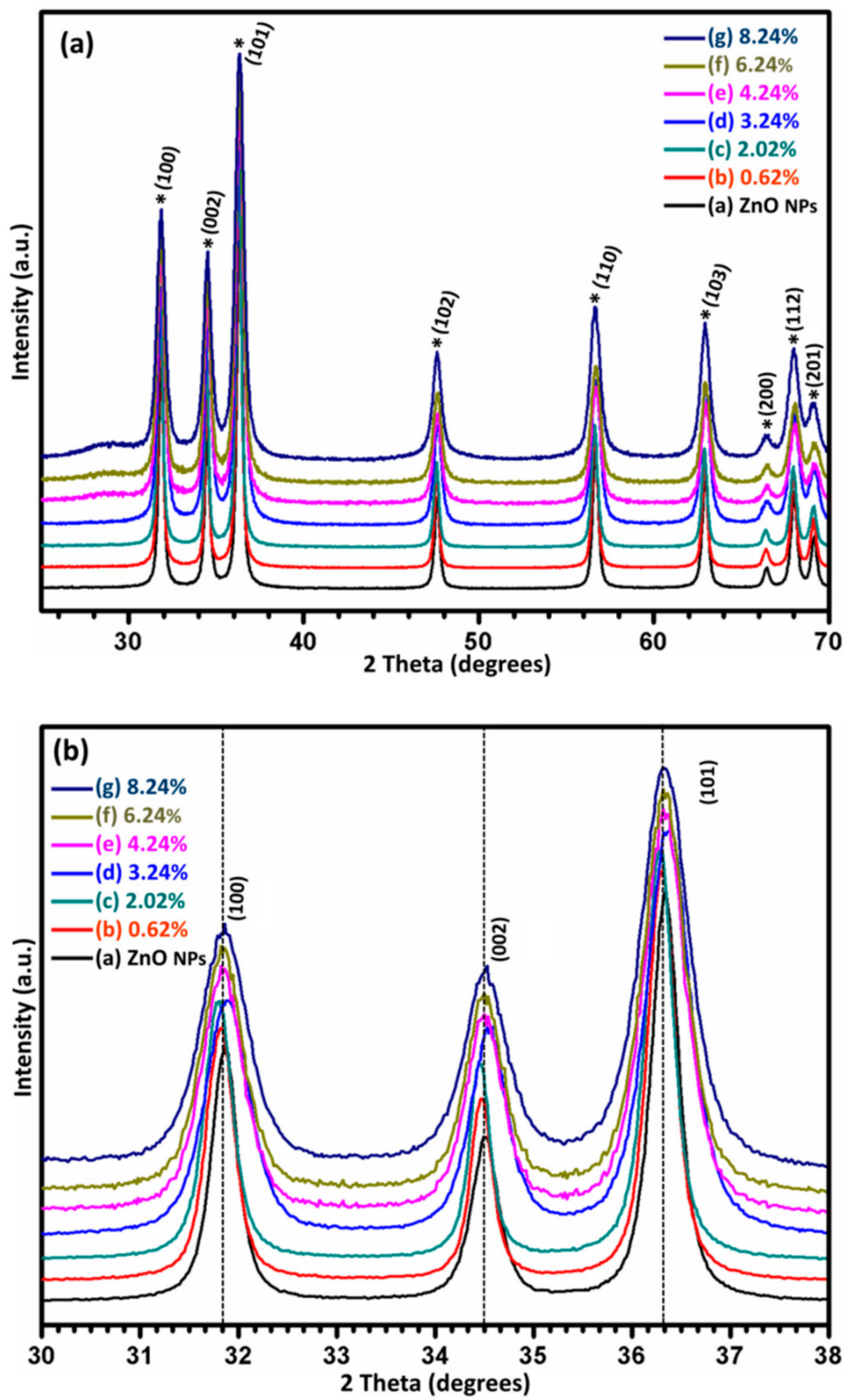

Figure 1. (a) XRD patterns of the set of pure $\mathrm{ZnO}$ and Ce-doped $\mathrm{ZnO}(\mathrm{CZO})$ samples. $\left(^{*}\right) \mathrm{ZnO}$. (b) Zoom of the XRD patterns obtained for the undoped and doped samples. The Bragg's angles shift

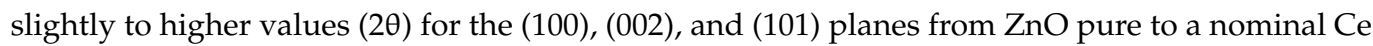
content of 3.24 atomic $\%$.

A very slight shift in the peak position is observed as shown in Figure $1 \mathrm{~b}$ for instance for the (002) peak. For the lowest Ce contents, the peak shifts toward lower angles which would correspond with a lattice expansion due to Ce incorporation. The ionic radii of $\mathrm{Ce}^{3+}(1.03 \AA)$ and $\mathrm{Ce}^{4+}(0.97 \AA)$ are much larger than that of $\mathrm{Zn}^{2+}$ ion $(0.74 \AA)$, however for the higher Ce contents, the increase in ionic radii does not reflect on an increase in the lattice parameters. The changes in defect structure needed to accommodate the charge imbalance could compensate the otherwise expected increase of the cell volume. This fact would be in agreement with the increase in the width of the diffraction peaks observed for the samples with Ce nominal content from 4.24 to 8.24 atomic\%, as shown in Figure 2a for the three main diffraction peaks (shown in Figure 1b). The variation of the full-width half-maximum (FWHM) with the Ce content could indicate that Ce-doping decreased the crystalline quality due to a decrease either of the crystallite size (CS) or to the major presence of point and disorder defects. 

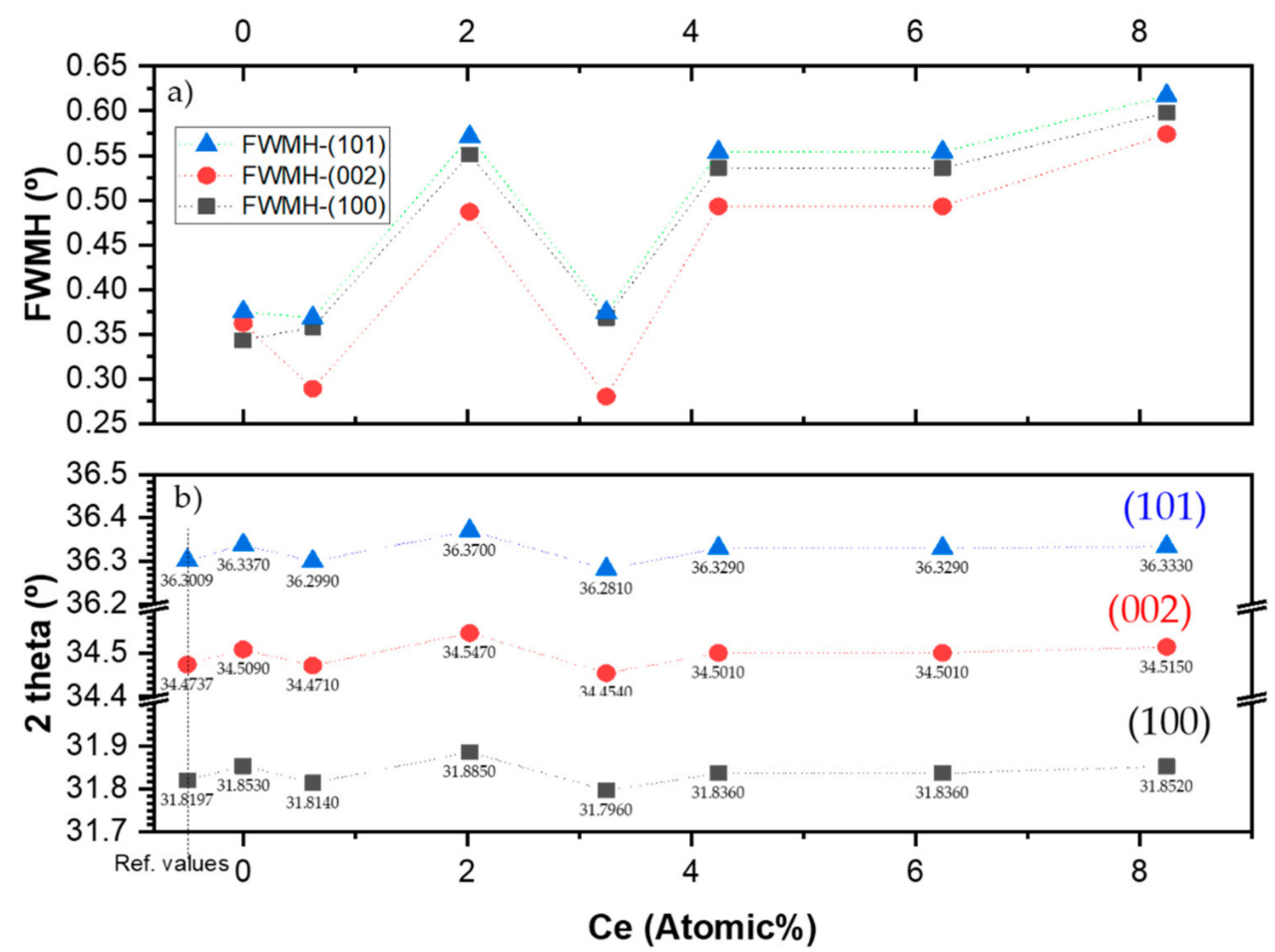

Figure 2. (a) Estimation of full-width half-maximum (FWHM) $\left(^{\circ}\right)$ for pure $\mathrm{ZnO}$ and $\mathrm{CZO}$ samples considering the most important diffraction peaks. (b) Estimation of diffraction peak shift of pure and Ce-doped ZnO. All the Ce contents indicated are nominal.

The average CS for all the synthesized samples was estimated from the FWHM of the (100), (002), and (101) diffraction peaks using Scherrer's formula. The calculated data and the error in the weighted mean are presented in Figure 3. The estimated CS shows a variation with the Ce content decreasing with the Ce nominal composition, except for the Ce- doped $\mathrm{ZnO}$ (3.24 atomic\%) sample, with a pronounced increase of CS. Higher concentrations of Ce could produce the accumulation of Ce atoms in or near the boundary of ZnO NPs, resulting in a decreased diffusion rate, which prevents the growth of NPs, so that the CS decreases gradually. This phenomenon has also been observed in other studies $[17,18]$. Based on XRD data, the lattice parameters have been calculated from $1 / \mathrm{d}(\mathrm{hkl})^{2}=\left[\left(\mathrm{h}^{2}+\mathrm{k}^{2}+\mathrm{hk}\right) / \mathrm{a}^{2}\right]+\mathrm{l}^{2} / \mathrm{c}^{2}$, where dhkl is the inter-planar distance, (hkl) are the Miller indexes and ' $a$ ' and ' $c$ ' are lattice constants. The calculated values of ' $a$ ' and ' $c$ ' for undoped $\mathrm{ZnO}$ are 3.247(1) and 5.195(9) $\AA$. As expected from the slight shift observed in the peak positions, no relevant differences on lattice parameters have been found (Figure 4).

FESEM images have been recorded to study the morphology of the NPs (Figure 5). The FESEM micrograph of the pure $\mathrm{ZnO}$ sample shows spherical-equiaxial particles (Figure 5a), while CZO samples consist of a mixture of relatively spherical-equiaxial and rice-grain shaped particles (Figure 5b-d). Generally, a high density of non-agglomerated particles appears in all samples. The sizes of CZO particles are about 30.6 $\pm 5.7,25.7 \pm 5.6,25.1 \pm 4.1$, $17.2 \pm 4.2,16.1 \pm 3.1,14.4 \pm 3.5$ and $12.8 \pm 3.3 \mathrm{~nm}$ for $0,2.02,3.24,4.24,6.24$, and 8.24 atomic $\%$, respectively. The sample with the 3.24 atomic\% content (Figure $5 \mathrm{c}$ ) shows similar morphologies to those for the samples with 8.24 atomic\% Ce, however, as it can be seen in Figure 5d, smaller spherical particle sizes are obtained when the highest doping concentration is used. 


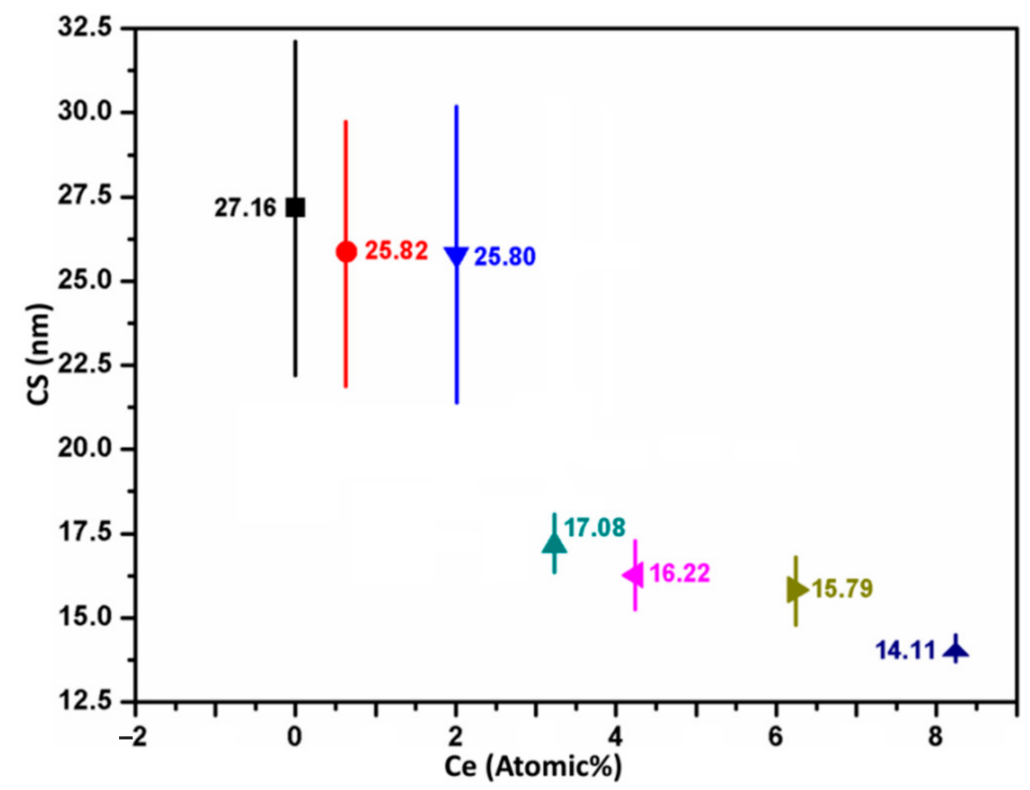

Figure 3. Calculated crystallite size (CS) (in angstrom) by Scherrer's Formula for pure and Ce-doped ZnO samples taking into account the three most important diffraction peaks. All the Ce contents indicated are nominal.

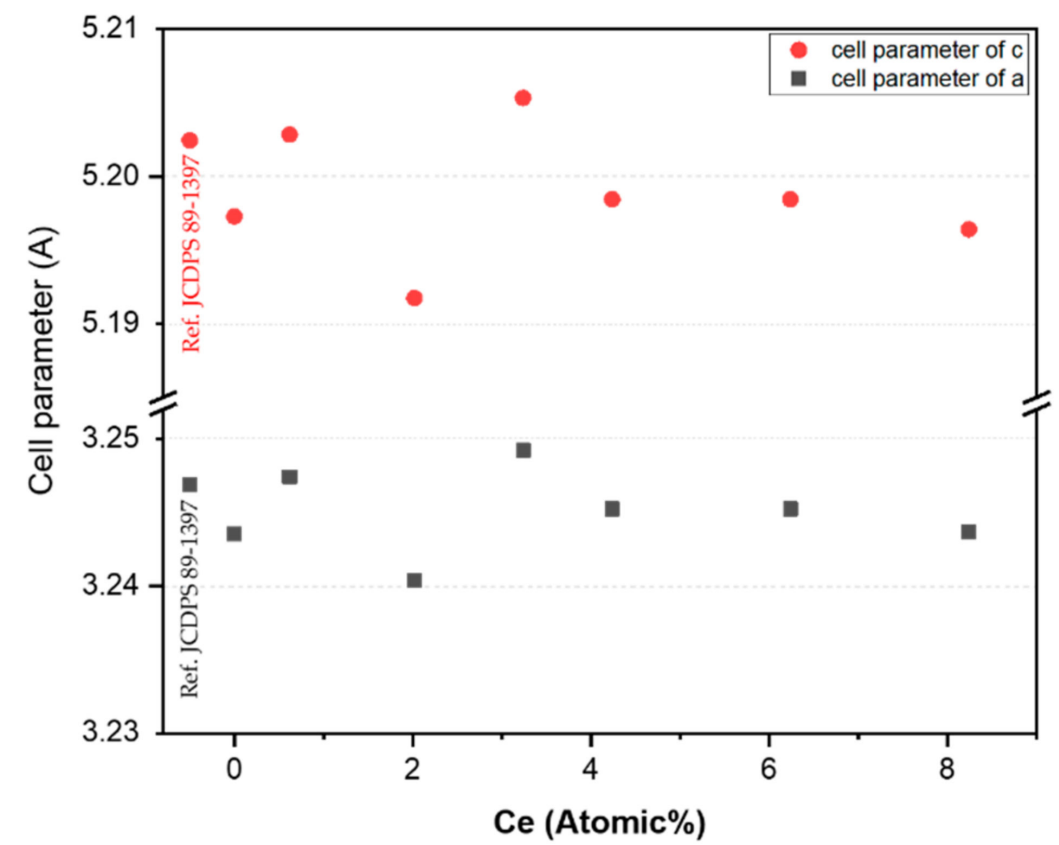

Figure 4. Evolution of the lattice parameters (a in black; $c$ in red) with dopant concentration. All the Ce contents indicated are nominal. 

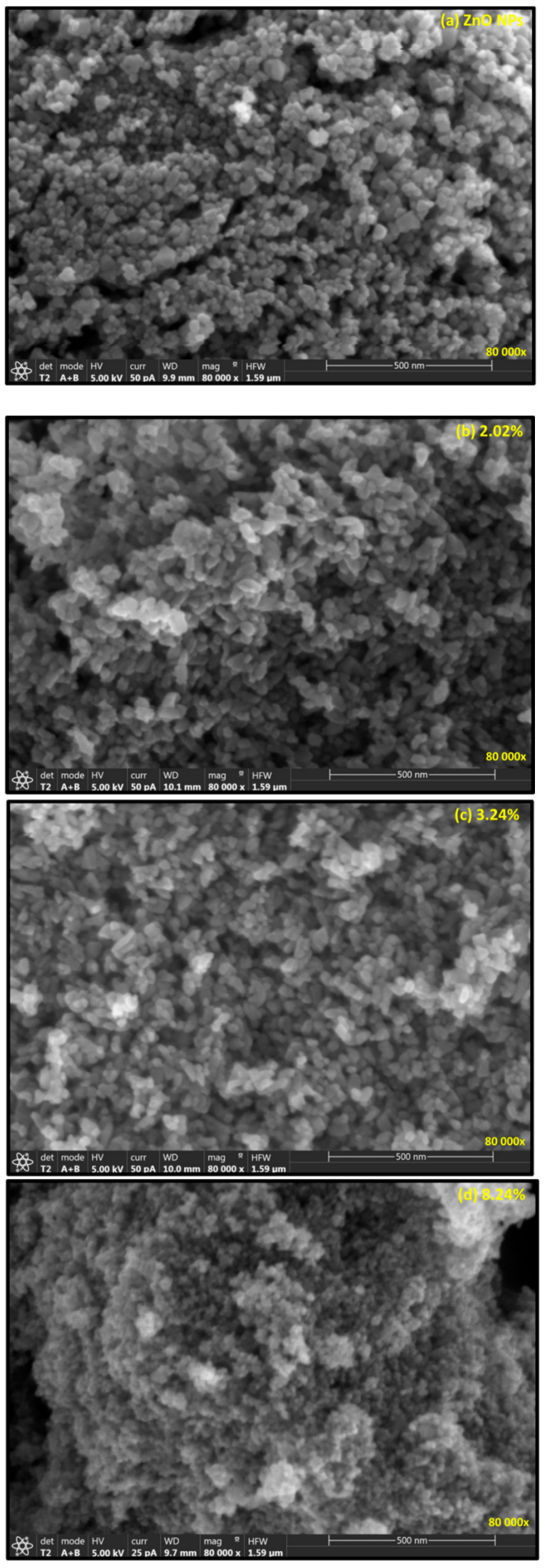

Figure 5. High magnification FESEM images of synthesized samples with different Ce atomic\% of: (a) ZnO NPs, (b) $2.02 \%$, (c) $3.24 \%$, and (d) $8.24 \%$. All the Ce contents indicated are nominal. 
EDS spectra of $\mathrm{ZnO}$ and $\mathrm{CZO}$ samples were performed to analyze the elemental composition (Figure 6). The spectrum from the pure $\mathrm{ZnO}$ sample (Figure 6a) shows a nearly stoichiometric composition. A typical spectrum from the doped samples is shown in Figure 6b, in particular, the spectrum corresponding to the 3.24 atomic $\%$ Ce sample was selected. The peaks for $\mathrm{Zn}, \mathrm{Ce}$, and $\mathrm{O}$ elements are clearly visible. Particularly, the Ce signal at around $4.85 \mathrm{keV}$ confirmed Ce-doping, although the amount of Ce is lower than the nominal composition. The negligible presence of $\mathrm{C}$ comes from the carbon-coated crucibles used in the measurements.
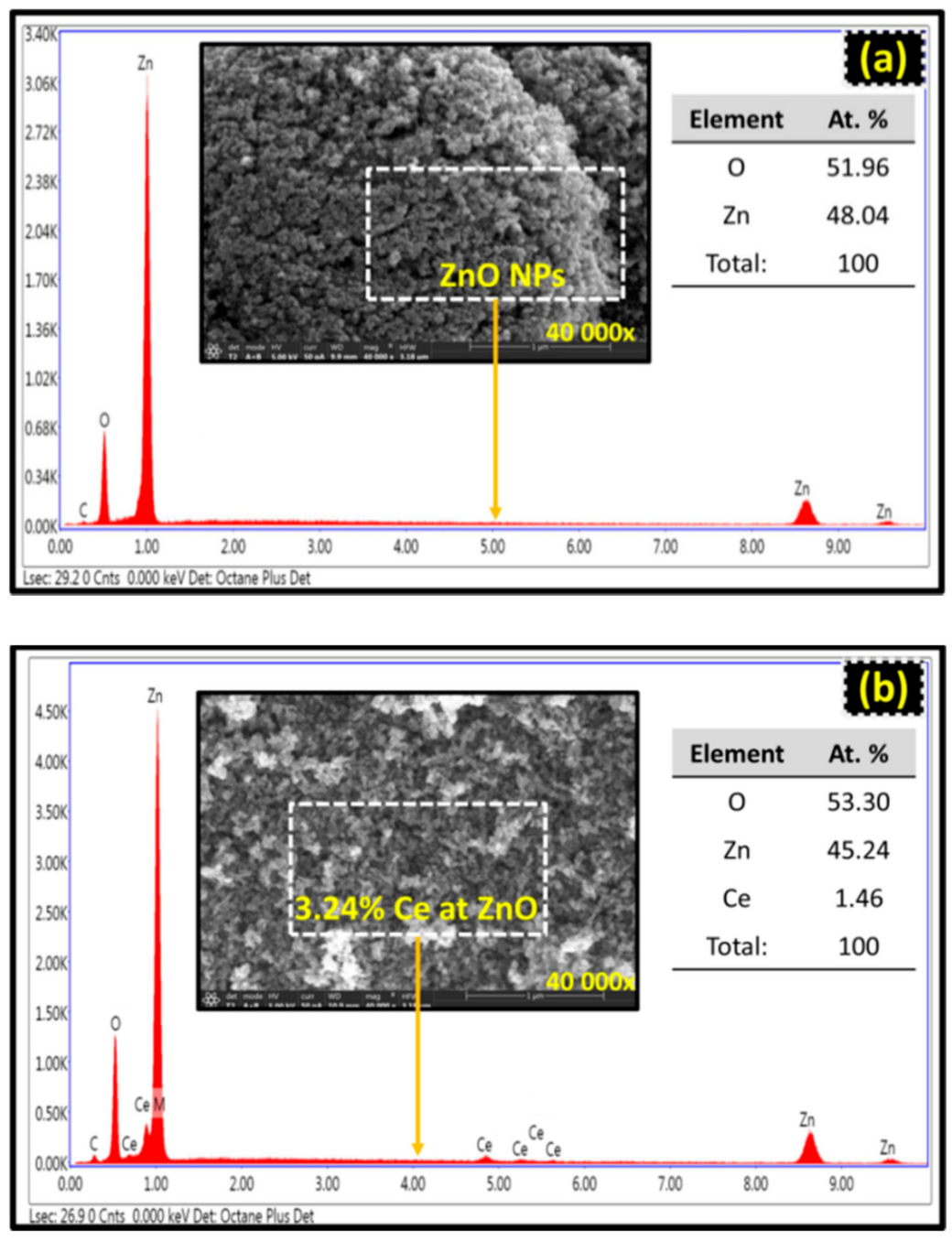

Figure 6. EDS spectra and elemental analysis for synthesized samples of: (a) pure ZnO, and (b) CZO with 3.24 atomic\%. All the Ce contents indicated are nominal.

The morphology and microstructure of the CZO samples were further analyzed by TEM and HRTEM (Figure 7). The TEM micrographs clearly show well-formed NPs. HRTEM images show clear lattice fringes which correspond to the d-spacing of the (002) plane in the wurtzite structure (see inset in Figure $7 \mathrm{a}-\mathrm{c}$ ). The measured distances between adjacent lattices planes are 2.63, 2.64, and $2.66 \AA$, for $3.24,4.24$, and 6.24 atomic\% Ce doped samples, respectively. The increase of d-spacing of the (002) plane proves that the Ce ions have been successfully incorporated into the $\mathrm{ZnO}$ lattice since the radius of $\mathrm{Ce}$ is larger than $\mathrm{Zn}$. 

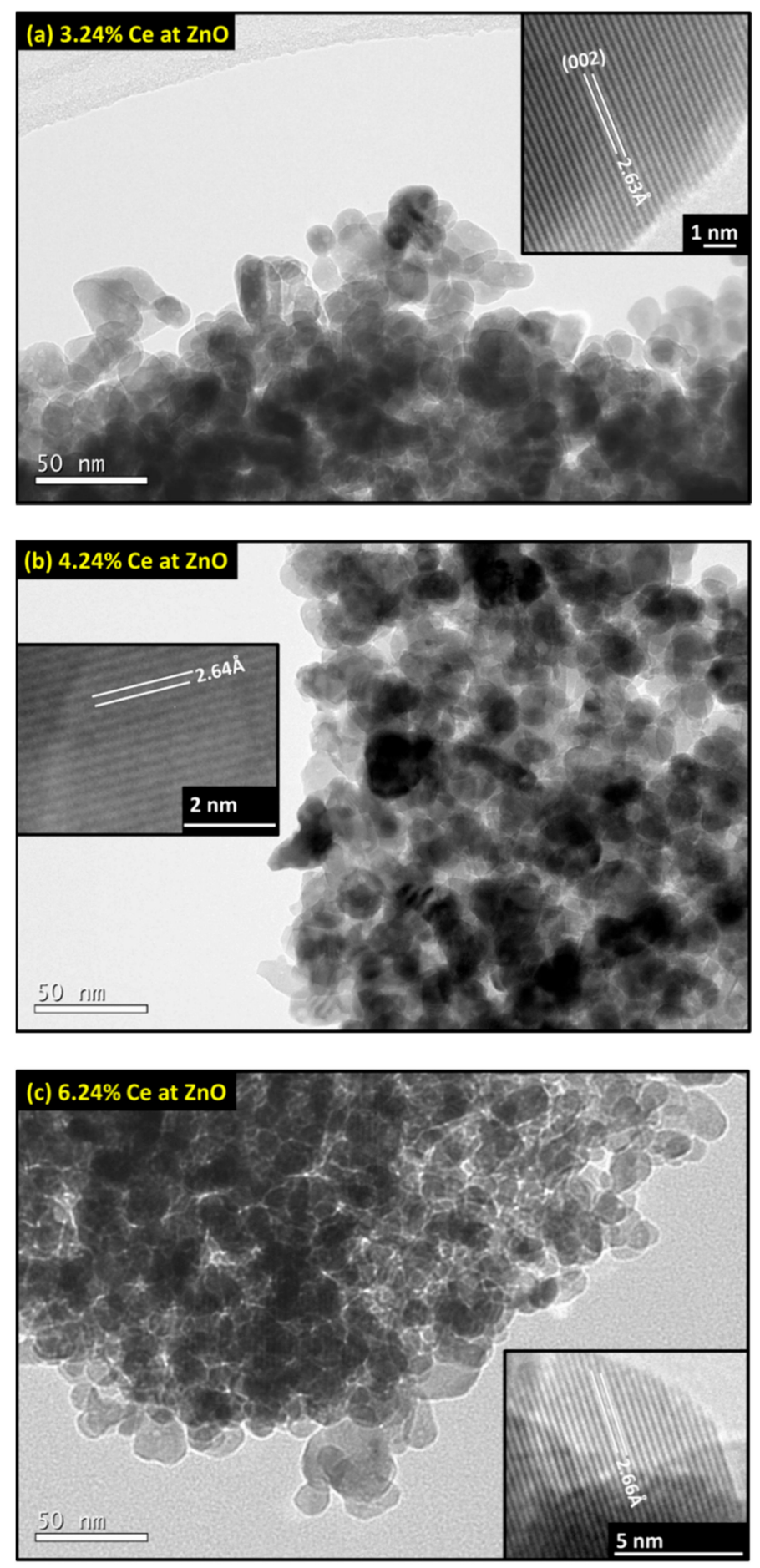

Figure 7. TEM and HRTEM images for synthesized samples with Ce atomic $\%$ of: (a) $3.24 \%$, (b) $4.24 \%$, and (c) $6.24 \%$. All the Ce contents indicated are nominal.

Figure 8a shows the UV-vis optical absorption curves. All the CZO samples have strong absorption at 388-390 $\mathrm{nm}(3.2 \mathrm{eV})$, which corresponds to the band to band absorption. The samples with the lower Ce content show an absorption band in the green region that corresponds to transitions associated to point defects such as oxygen or zinc vacancies. As the dopant concentration increases, the intensity of this band decreases, however, the non-linear part of the absorption curve begins at lower wavelengths, indicating a major role of stresses induced by the dopant. The direct band-gap energy was calculated from the derivative of the absorption curve. The bandgap is not appreciably modified upon 
Ce-doping, for all the Ce concentrations studied (Figure 8b). However, the shape of the derivative of the absorption curves shows appreciable differences when pure $\mathrm{ZnO}$ is compared to CZO samples.
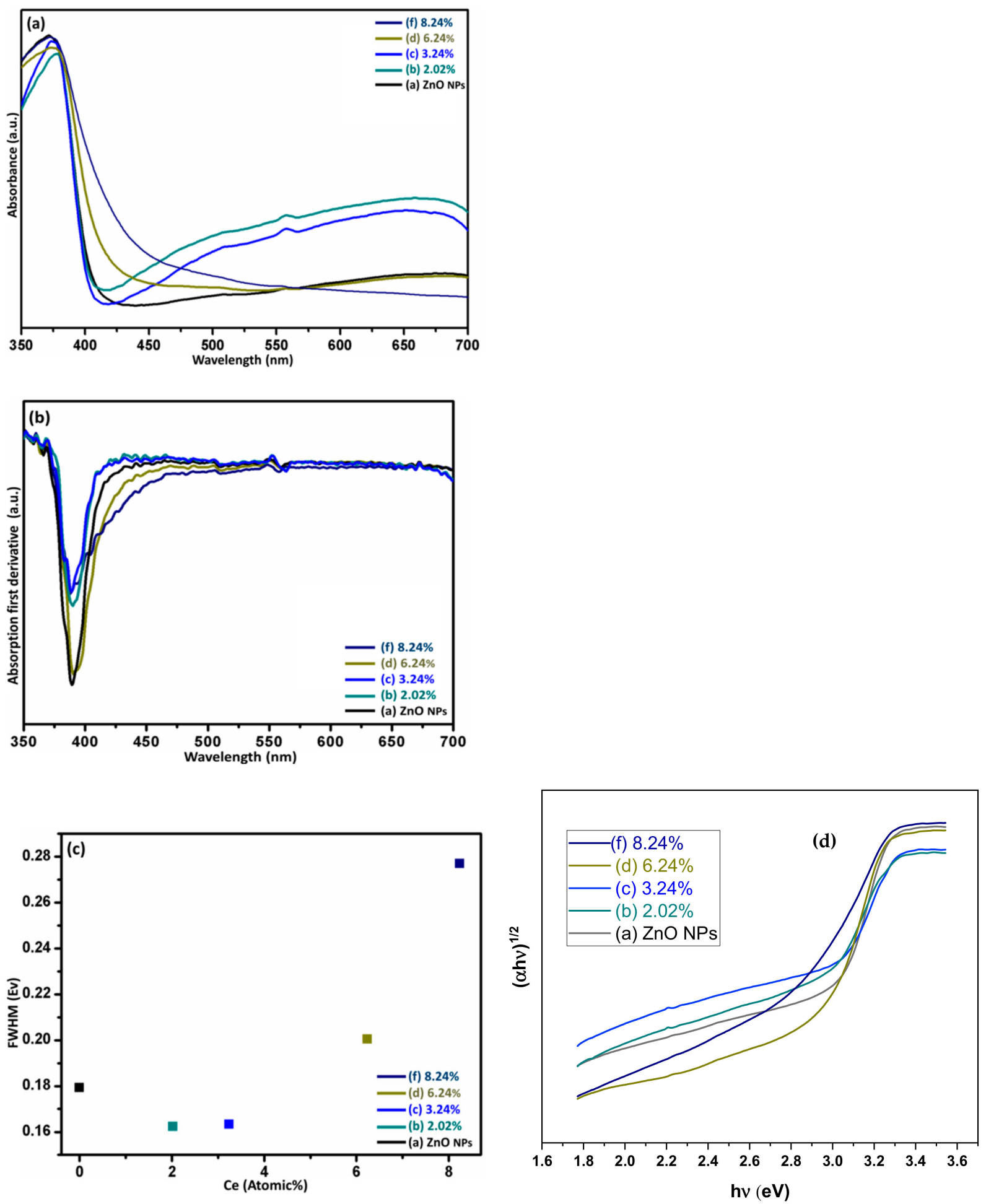

Figure 8. (a) Absorption spectra of pure $\mathrm{ZnO}$ and $\mathrm{CZO}$ samples. (b) First derivative of the spectra shown in part (a). (c) Evolution of first derivative FWHM of the absorption spectra. (d) Tauc plot from absorbance spectra of part (a). All the Ce contents indicated are nominal. 
An accurate calculation of the Urbach energy was not possible due to the overlapping of the defect components; however, a rough estimation of the broadening associated with the crystal disorder could be made from the FWHM of the derivative as shown in Figure 8c. For the undoped sample and the two lower dopant concentrations, the values of FWHM are quite similar between 0.16 and $0.18 \mathrm{eV}$; for the most heavily doped samples, the values are above $0.2 \mathrm{eV}$, reaching $0.27 \mathrm{eV}$ for the sample with the highest Ce content.

The influence of the incorporation of Ce on the luminescent properties was also studied using PL measurements at RT. All the spectra show a complex UV band, which corresponds to several emissions in the near band edge range of $\mathrm{ZnO}$ as well as a visible wide band between 1.77 and $2.61 \mathrm{eV}(475$ and $700 \mathrm{~nm})$ related to different defects. The spectra of the CZO samples show a shift of the UV band towards lower energies due to a decrease in the intensity of the higher energy components, as shown in Figure 9a. The changes produced in the relative intensity of the different luminescence bands are also apparent from the chromaticity diagrams shown in Figure 9b, where the different color of the emitted light (CIE coordinates) by each sample is much better appreciated. The CIE coordinates shown are the result of the addition of all the luminescence bands; hence a change in the relative intensity of any of them would produce a change in the color of the emitted light. The spectra consist of the convolution of the different bands, hence small changes in the relative intensity might be difficult to appreciate in the spectra, but can be more clearly appreciated from the perceived color. Compared with the pure $\mathrm{ZnO}$ sample, the high energy component of the UV emission band in the CZO samples shows a lower intensity [18]. In particular, the lowest intensity corresponds to the sample with 3.24 atomic\% Ce. Since this emission originated from the recombination of free excitons in $\mathrm{ZnO}$ (near-band-edge (NBE) emission) [28], the decrease in its intensity could indicate a lower electron-hole recombination rate and it may result in a higher photocatalytic activity $[15,29,30]$. In this case, the doped sample with 3.24 atomic\% Ce should have the highest photocatalytic activity (PCA), and the pure ZnO NPs should have the lowest PCA photocatalytic activity, which is consistent with the actual photocatalytic performance as we will discuss later.

The defect emission in PL spectra of $\mathrm{ZnO}$ consists typically in the broadband extending over the visible range, which is the result of the overlapping of several emissions related to the presence of deep levels (DLE). The main emission is the typical green-yellow emission of $\mathrm{ZnO}$ that has been extensively studied but is still controversial [31]. Its origin is not fully understood, although it is known that it is related to transitions involving native point defects, oxygen vacancies $\left(\mathrm{V}_{\mathrm{O}}\right)$, oxygen interstitials $\left(\mathrm{O}_{\mathrm{i}}\right)$, zinc vacancies $\left(\mathrm{V}_{\mathrm{Zn}}\right)$, zinc interstitials $\left(\mathrm{Zn}_{\mathrm{i}}\right)$, oxygen antisites $\left(\mathrm{O}_{\mathrm{Zn}}\right)$, and zinc antisites $\left(\mathrm{Zn}_{\mathrm{O}}\right)$ [32,33]. According to previous studies, the calculated energy levels for these defects [34] are all compatible with the emissions recorded from our samples.

The photocatalytic activity of $\mathrm{ZnO}$ :Ce samples has been studied by different research groups $[14,35,36]$. The photobleaching of an organic dye, methylene blue (MB), a typical contaminant in the textile industry, in aqueous solution $(2.5 \mathrm{ppm})$, was used as a model to evaluate the photocatalytic activity of the synthesized CZO samples with different Ce contents $(0,0.62,2.02,3.24,4.24,6.24$ and 8.24 atomic\%). For comparison, the photocatalytic experiments of all the CZO samples were carried out under identical conditions. Figure 10a-f shows the evolution with time of the absorbance curves of the different samples. The intensity of the characteristic absorption peak of MB molecules at $665 \mathrm{~nm}$ decreases gradually. This absorption band maximum, which corresponds to the dye, shows a steady decreasing trend indicating that the complete destruction of the dye takes place. This effect is more pronounced in the photocatalysts doped with 2.02 and 3.24 atomic\% Ce (Figure 10c,d). 

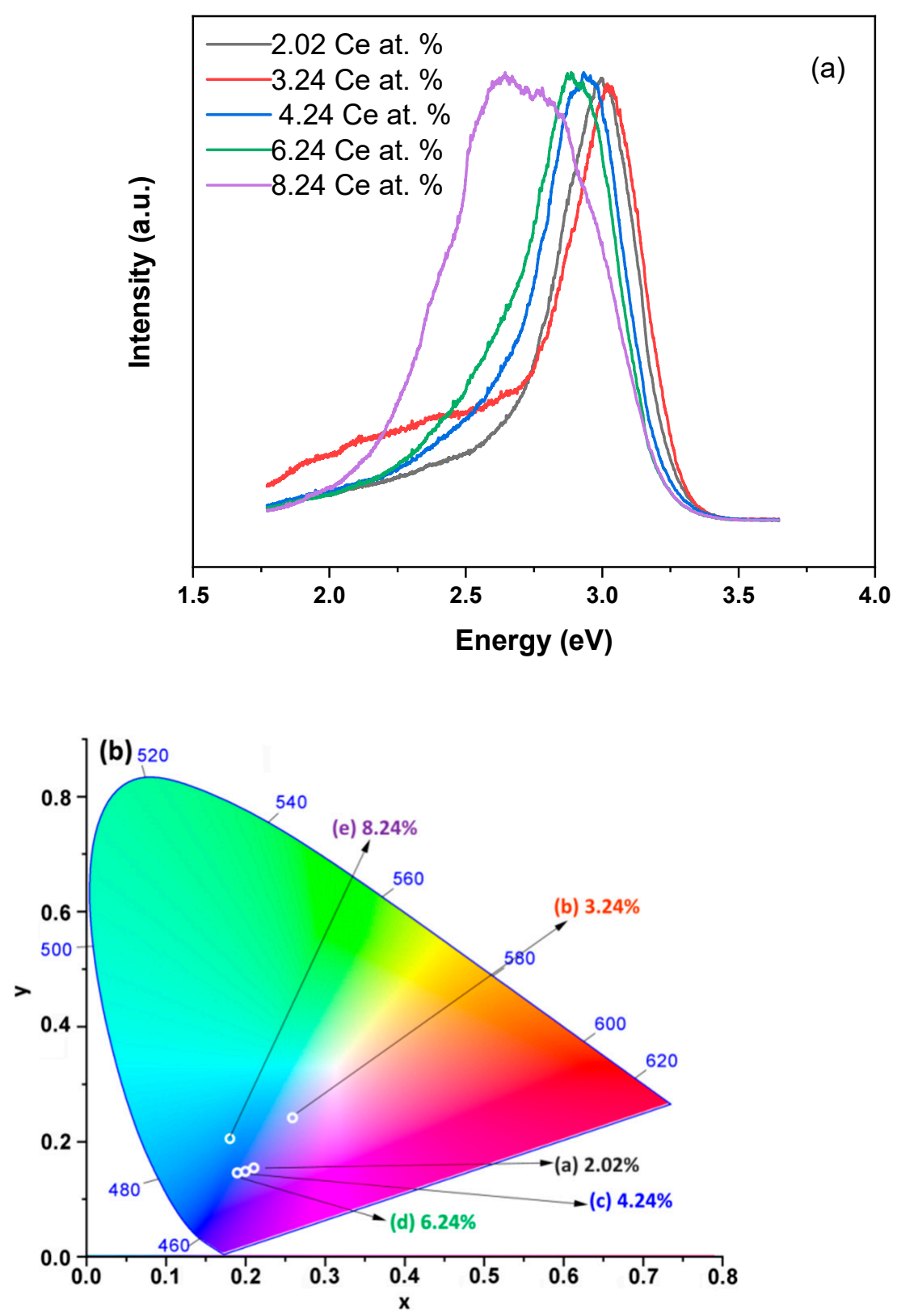

Figure 9. (a) Room-temperature normalized PL spectra of pure $\mathrm{ZnO}$ and $\mathrm{CZO}$ samples. (b) Chromaticity Diagram. All the Ce contents indicated are nominal.

After exposure to UV light for only $30 \mathrm{~min}$ the elimination percentage reached was higher than $70 \%$, although not all the samples showed the same activity as observed in the curves of Figure 11. An increase of the PCA was observed up to a Ce content of 3.24 atomic $\%$, then, the PCA decreased moderately for samples with Ce content up to 6.24 atomic\%. Further increasing the Ce content (nominally $8.24 \%$ ), caused a dramatic reduction in the degradation rate (see inset of Figure 11b). The effect of particle size on the PCA of $\mathrm{ZnO}$ has been previously reported as well as the optimum size for which photocatalytic activity was maximized. It has been proven that when the particle sizes of nanostructures increase beyond the optimum size, the photocatalytic activity decreases due to the decrease in surface area [37]. In our case, the size of the NPs decreases with increasing Ce-doping concentration. So, the degradation efficiency of MB for the sample with $3.24 \%$ is higher than that for the $0,0.62$, and 2.02 atomic\% Ce samples. However, as the doping concentration further increases, the degradation efficiencies of $\mathrm{MB}$ for samples with 4.24, 6.24, and 8.24 atomic\% Ce are lower as observed in Figure 12. 

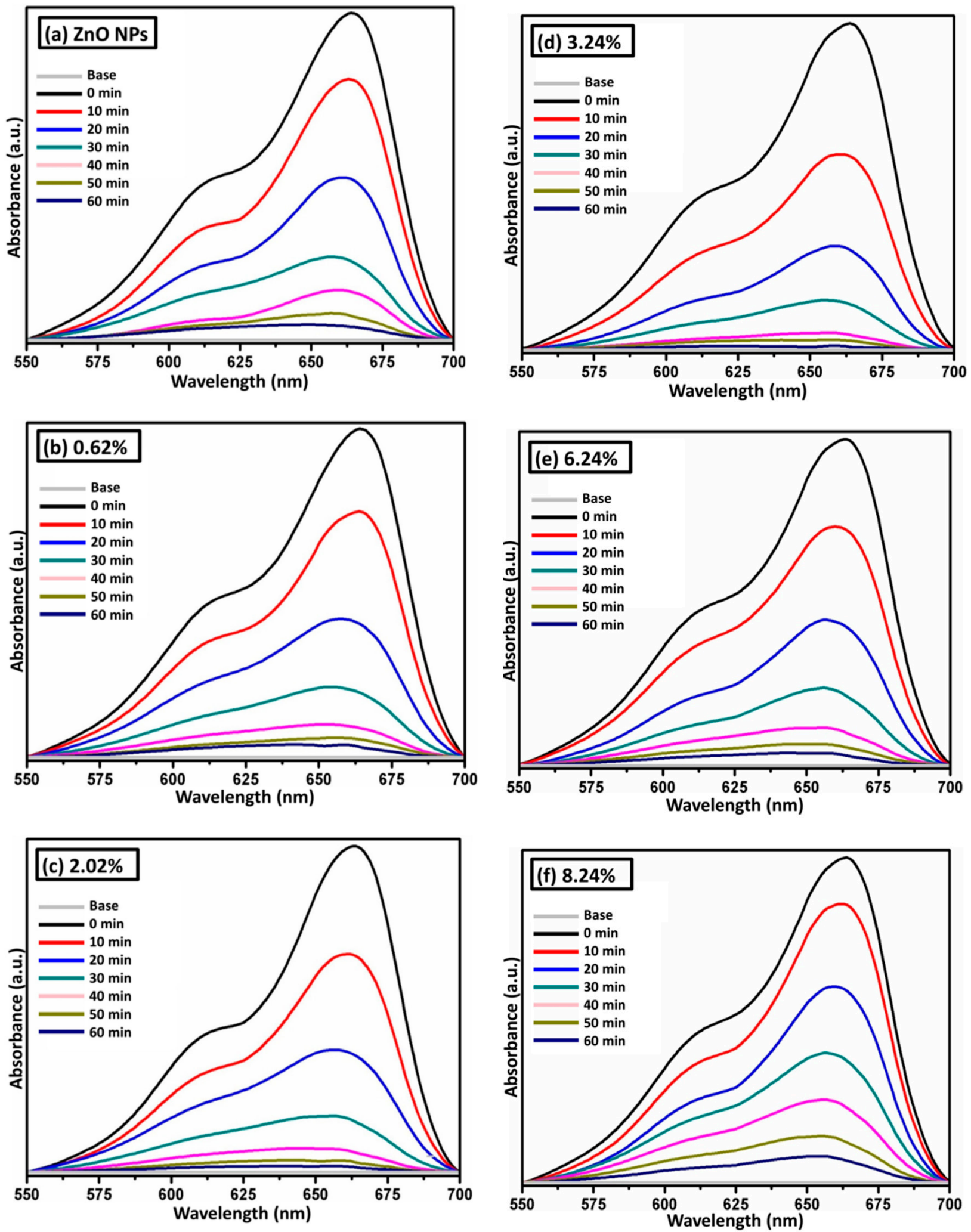

Figure 10. Changes of the UV-visible absorption spectra of MB solution with increasing UV light irradiation time in the presence of photocatalysts doped with different Ce content: (a) Undoped ZnO, (b) 0.62 nominal at Ce\%; (c) 2.202 nominal at $\mathrm{Ce} \%$; (d) 3.24 nominal at $\mathrm{Ce} \%$; (e) 6.24 nominal at $\mathrm{Ce} \%$ and (f) 8.24 nominal at $\mathrm{Ce} \%$. 

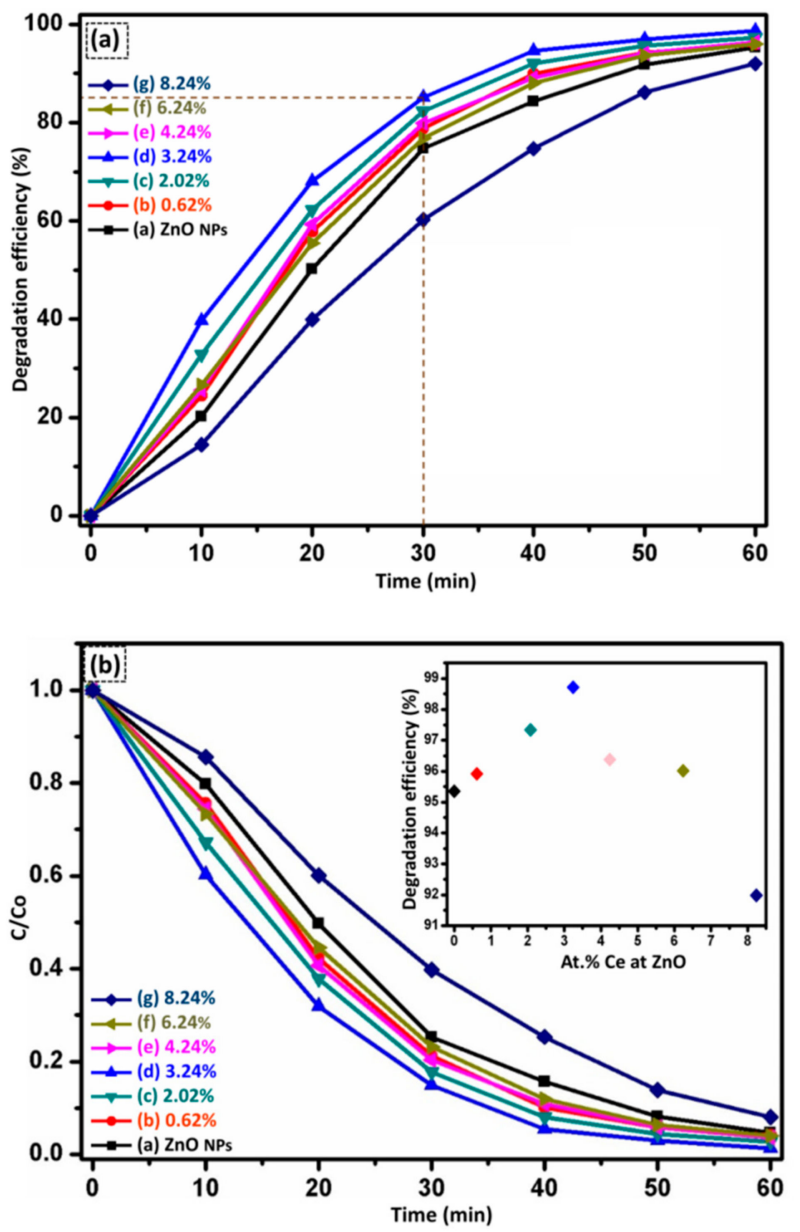

Figure 11. (a) Percentage of photodegradation of MB with CZO NPs vs. irradiation time (min). (b) C/Co for MB dye of the CZO NPs vs. irradiation time ( $\mathrm{min})$, the percentage of photodegradation vs. percentage of Ce-doping content after $60 \mathrm{~min}$ of UV irradiation is shown in the inset. All the Ce contents indicated are nominal.

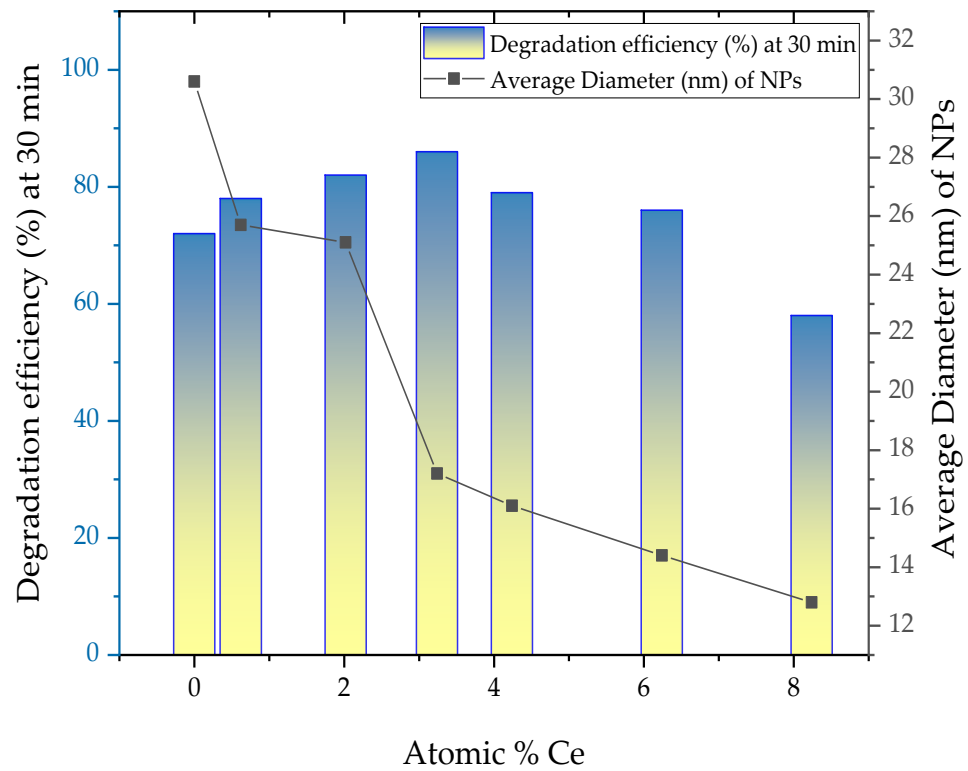

Figure 12. Degradation efficiency (\%) for $30 \mathrm{~min}$ of irradiation and average catalyst diameter with different atomic $\%$ of Ce. 
However, the particle size is not the only factor that affects the PCA. For instance, comparing the response from pure ZnO NPs to doped particles with similar particle size, the photocatalytic efficiency is higher for the doped sample. The presence of Ce ions in the $\mathrm{ZnO}$ host would then enhance the PCA, irrespective of the particle size effect and at atomic\% lower than $8 \%$ of Ce (Figure 12). RE ions are known for their ability to trap electrons, which could effectively reduce the recombination of photogenerated electronhole pairs $[10,11]$. The $4 \mathrm{f}$-shell of an RE ion can accept or donate electrons $\left(\mathrm{e}^{-}\right)$from or to the energy bands of the host. Thus, the doping in $\mathrm{ZnO}$ can influence the photoreactivity by varying the recombination rate of electron-hole pairs by the reactions indicated in Equations (1)-(6).

$$
\begin{gathered}
\mathrm{ZnO}+h v \rightarrow \mathrm{e}^{-}+\mathrm{h}^{+} \\
\mathrm{Ce}^{4+}+\mathrm{e}^{-} \rightarrow \mathrm{Ce}^{3+} \\
\mathrm{Ce}^{3+}+\mathrm{O}_{2} \rightarrow{ }^{\bullet} \mathrm{O}_{2}^{-}+\mathrm{Ce}^{4+} \\
\bullet \mathrm{O}_{2}^{-}+\mathrm{H}^{+} \rightarrow{ }^{\bullet} \mathrm{OOH} \\
\bullet \mathrm{OOH}+\mathrm{H}^{+}+\mathrm{e}^{-} \rightarrow \mathrm{H}_{2} \mathrm{O}_{2} \\
\mathrm{H}_{2} \mathrm{O}_{2}+\mathrm{e}^{-} \rightarrow{ }^{\bullet} \mathrm{OH}+\mathrm{OH}^{-}
\end{gathered}
$$

In Figure $13 \mathrm{~b}$ a simplified model is depicted. $\mathrm{Ce}^{4+}$ easily traps the photo-excited electron, which then forms $\mathrm{Ce}^{3+}(4)$. The electrons trapped in $\mathrm{Ce}^{4+}$ sites are subsequently transferred to the adsorbed $\mathrm{O}_{2}$ by an oxidation process. $\mathrm{Ce}^{3+}$ will react with oxygen adsorbed onto the catalytic surface to produce superoxide ${ }^{\bullet} \mathrm{O}_{2}^{-}$radicals (5) which are then converted to active hydroxyl radicals $\left({ }^{\bullet} \mathrm{OH}\right)$ at the catalyst surface. They can then accelerate the photocatalytic reaction and lead to the partial or complete degradation of the organic pollutant MB $[29,36]$.

As shown from the PL spectra, the presence of Ce ions minimizes the recombination of photogenerated electron-hole pairs thus inducing the increase of ZnO PCA $[15,30]$. The photogenerated hole in the valence band $\left(\mathrm{h}^{+} \mathrm{BV}\right)$ caused by Ce-doping can also generate active ${ }^{\bullet} \mathrm{OH}$ formed by the decomposition of water or by the reaction of the hole with hydroxide $\left(\mathrm{OH}^{-}\right)$species. At the same time, the Ce-doping usually introduces more defects such as $\mathrm{V}_{\mathrm{O}}$ in the $\mathrm{ZnO}$ host. The $\mathrm{V}_{\mathrm{O}}$ can absorb the oxygen species (such as $\mathrm{O}_{2}$, $\mathrm{OH}^{-}$) and change them to high activity ${ }^{\bullet} \mathrm{O}_{2}^{-}$and ${ }^{\bullet} \mathrm{OH}$, accelerating the photocatalytic reaction as well. For the above reasons, PCA increases with Ce-doping. Nevertheless, once the Ce-doping concentration is higher than 3.24 atomic\%, the electrons and holes trapped by the dopant ions first recombine instead of transferring to the surface to take part in the photocatalytic reaction. Moreover, a high concentration of Ce in the $\mathrm{ZnO}$ surface likely decreases the active surface area of the particles available for absorbing photons, resulting in a decrease in hydroxyl radical generation. Hence the degradation efficiency also decreases.

To quantitatively understand the reaction kinetics of MB degradation, the plotted data of $\ln \left(C_{0} / C\right)$ versus photodegradation time is depicted in Figure 13a. These results clearly show a linear relationship with the irradiation time, indicating that the photodegradation of the dye follows a pseudo-first-order kinetics confirming the applicability of the LangmuirHinshelwood equation for each CZO photocatalyst. The inset of Figure 13a depicts the variations of apparent reaction rate constants $(k)$ values calculated from the slopes of the lines and the coefficient of linear regression. The results demonstrated that Ce atomic content in the range of $0.65-3.24 \%$ could be used to improve the PCA, but an excess of Ce content (from 4.24 to $8.24 \%$ ) could even be deleterious. 

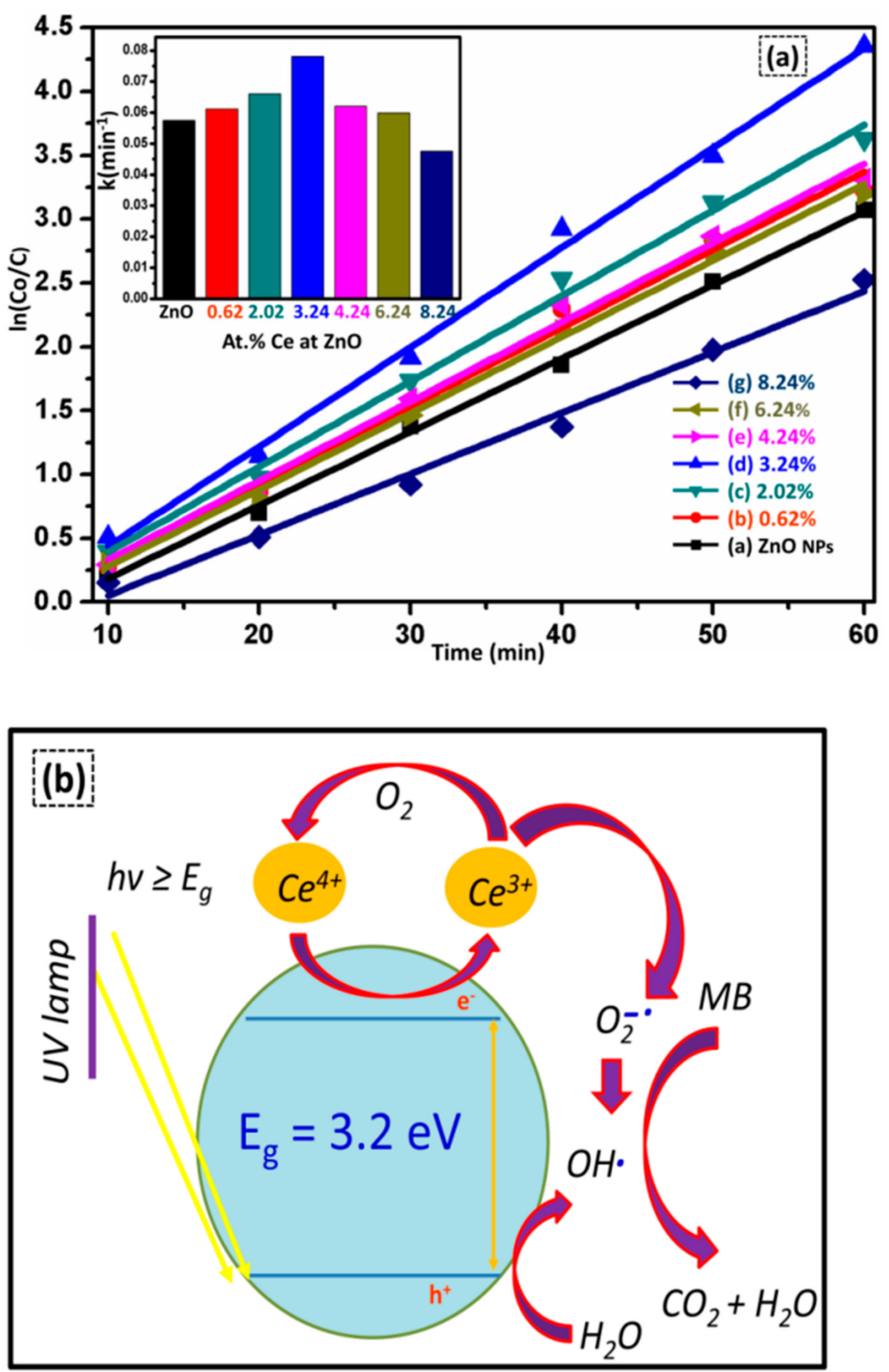

Figure 13. (a) Pseudo-first order kinetics for MB dyes in the presence of CZO NPs as photocatalysts, the rate constant $(k)$ for CZO NPs observed during photocatalytic degradation of MB under UV light irradiation is shown in the inset. (b) Correlation between the photodegradation efficiency and the properties of the photocatalysts. All the Ce contents indicated are nominal.

Accordingly, the obtained results demonstrate that a particular amount of Ce doping $(3.24 \% \mathrm{Ce})$ into $\mathrm{ZnO}$ is essential to degrade the MB dye completely. Therefore, at optimum Ce concentration (nominally 3.24\%), the as-prepared CZO samples had the higher photocatalytic efficiency (exhibiting photobleaching of $98.72 \%$ ) with the highest rate constant $\mathrm{k}=0.0781 \mathrm{~min}^{-1}$ (std. error: $\left.0.00192, \mathrm{R}^{2}=0.9449\right)$ and half life time $\left(\mathrm{t}_{1 / 2}\right)$ minimum (8.8751 min) only in $60 \mathrm{~min}$. Furthermore, it can also be concluded from Figures 11 and 13a that the prepared $\mathrm{CZO}$ photocatalysts exhibited better photocatalytic performances of the $\mathrm{MB}$ dye compared to other Ce-doped $\mathrm{ZnO}$ nanomaterial based photocatalysts reported in the literature $[13,14,37,38]$. 


\section{Experimental Details}

\subsection{Materials}

Zinc acetate dihydrate $\left(\mathrm{Zn}\left(\mathrm{CH}_{3} \mathrm{COO}\right)_{2} \cdot 2 \mathrm{H}_{2} \mathrm{O}\right.$, purity $>98 \%$, Sigma-Aldrich, St. Louis, $\mathrm{MO}, \mathrm{USA})$ and cerium acetate hydrate $\left(\mathrm{Ce}\left(\mathrm{CH}_{3} \mathrm{CO}_{2}\right)_{3} \cdot \mathrm{H}_{2} \mathrm{O}\right.$, purity $>99.9 \%$, Sigma-Aldrich) was used as zinc and cerium precursors, respectively. Polyvinylpyrrolidone- $-\mathrm{PVP}\left(\left(\mathrm{C}_{6} \mathrm{H}_{9} \mathrm{NO}\right)_{\mathrm{n}}\right.$ $\mathrm{Mw}=40,000 \mathrm{~g} / \mathrm{mol}$, Sigma-Aldrich) and ethylene glycol-EG $\left(\mathrm{C}_{2} \mathrm{H}_{6} \mathrm{O}_{2}\right.$, purity $>99.9 \%$, Sigma-Aldrich) were added as a capping agent and solvent, respectively. All the precursor chemicals were reagent grade, and therefore, no further purification was applied.

\subsection{Synthesis Process}

The synthesis of the CZO NPs was achieved in a polyol-mediated process. For this purpose, the stoichiometric amount of zinc acetate and cerium acetate was dissolved in $50 \mathrm{~mL}$ of pure EG, and simultaneously PVP $(5000 \mathrm{mg})$ was added to the solution at RT stirring vigorously for 15 min until a colorless and uniform solution was obtained. Subsequently, the mixture was transferred into a $100 \mathrm{~mL}$ three-neck flask equipped with a reflux condenser, a mechanical stirrer, and a thermometer. Each precursor solution was then continuously stirred, and heated to a temperature of $185^{\circ} \mathrm{C}$, at a constant heating rate of $7.5^{\circ} \mathrm{C} / \mathrm{min}$. Since the zinc acetate and cerium acetate dissolved gradually, no nucleation or growth process occurred during the heating stage. However, when the temperature of the precursor solution reached $185^{\circ} \mathrm{C}$, the nucleation process started due to the water contained in the zinc acetate dihydrate and cerium acetate hydrate. Immediately, ultrapure deionized water was injected into the hot precursor solution with a hydration ratio of 10 using a syringe pump (KDS200, KD Scientific, Holliston, MA, USA) at a constant rate of $1 \mathrm{~mL} / \mathrm{s}$. Upon injection of the water, the solution became milky. The reaction continued for $30 \mathrm{~min}$, after which the system was cooled down to RT. The particles were separated from the reaction medium by several centrifugation stages at $4000 \mathrm{rpm}$ for $15 \mathrm{~min}$, and then washed repeatedly with deionized water and ethanol to remove the excess of physically adsorbed PVP and EG. The nominal and stoichiometric composition of each of the $\mathrm{Zn}_{1-x} \mathrm{Ce}_{\mathrm{x}} \mathrm{O}$ NPs prepared with different atomic $\%$ of Ce are shown in Table 1.

Table 1. Nominal and stoichiometric compositions of the $\mathrm{Zn}_{1-\mathrm{x}} \mathrm{Ce}_{\mathrm{x}} \mathrm{O}$ NPs

\begin{tabular}{|c|c|c|c|c|c|}
\hline $\mathrm{X}=$ atomic $\%$ & $\mathrm{Zn}_{1-\mathrm{x}} \mathrm{Ce}_{\mathrm{x}} \mathrm{O}$ & $\mathrm{mg}^{1} / 50 \mathrm{~mL} \mathrm{EG}$ & $\mathrm{mg}^{2} / 50 \mathrm{~mL} \mathrm{EG}$ & $\begin{array}{c}\text { mg } \\
\text { Ratio Zn/PVP }\end{array}$ & $\begin{array}{c}\text { molar } \\
\text { Ratio of } \mathrm{Zn} / \mathrm{PVP}\end{array}$ \\
\hline 0 & $\mathrm{ZnO}$ & 1348.84 & 一 & 0.270 & 0.049 \\
\hline 0.62 & $\mathrm{Zn}_{0.9938} \mathrm{Ce}_{0.0062} \mathrm{O}$ & 1332.87 & 12.0179 & 0.267 & 0.049 \\
\hline 2.02 & $\mathrm{Zn}_{0.9798} \mathrm{Ce}_{0.0202} \mathrm{O}$ & 1297.51 & 38.6610 & 0.260 & 0.047 \\
\hline 3.24 & $\mathrm{Zn}_{0.9676} \mathrm{Ce}_{0.0324} \mathrm{O}$ & 1267.41 & 61.3359 & 0.253 & 0.046 \\
\hline 4.24 & $\mathrm{Zn}_{0.9576} \mathrm{Ce}_{0.0424} \mathrm{O}$ & 1243.22 & 79.5570 & 0.249 & 0.045 \\
\hline 6.24 & $\mathrm{Zn}_{0.9376} \mathrm{Ce}_{0.0624} \mathrm{O}$ & 1196.11 & 115.0493 & 0.239 & 0.044 \\
\hline 8.24 & $\mathrm{Zn}_{0.9176} \mathrm{Ce}_{0.0824} \mathrm{O}$ & 1150.60 & 149.3293 & 0.230 & 0.042 \\
\hline
\end{tabular}

${ }^{1}\left(\mathrm{Zn}\left(\mathrm{CH}_{3} \mathrm{COO}\right)_{2} \cdot 2 \mathrm{H}_{2} \mathrm{O}\right) ;{ }^{2} \mathrm{Ce}\left(\mathrm{CH}_{3} \mathrm{CO}_{2}\right)_{3} \cdot \mathrm{H}_{2} \mathrm{O}$; In every synthesis: $5000 \mathrm{mg}$ of PVP/50 mL EG). The calculated yield values were $40-45 \%$.

Finally, the particles were dried in an oven at $80{ }^{\circ} \mathrm{C}$ for $12 \mathrm{~h}$. Ce concentration was varied in the range 0 to 8.24 atomic $\%$. In particular, atomic\% concentrations of $0.62,2.02$, $3.24,4.24,6.24$, and 8.24 were used. A gradual increase in yellow color with the increase in Ce content was observed.

\subsection{Characterization Techniques}

The crystallographic structure of all the powder samples was characterized using an X-ray diffractometer (Philips $X^{\prime}$ pert, Malvern, UK)) in a wide range of the Bragg angle $2 \theta\left(25^{\circ}<2 \theta<70^{\circ}\right)$ using $\mathrm{CuK} \alpha$ radiation $(\lambda=1.5406 \AA)$. The scanning rate was set at 
$0.02^{\circ}$, and counting time per step was $10 \mathrm{~s}$. The averages crystallite sizes were derived considering the three most intense diffraction peaks by Scherrer's formula. The equation is defined by the relation $L=0.9 \times \lambda / \beta \cos \theta$, where $L$ is the average crystallite size (in $\AA$ ), $\lambda$ the X-ray wavelength (in $\AA$ ), $\beta$ the full-width half-maximum (FWHM) and $\theta$ is the position of the diffraction angle peak (in rad). The lattice parameters were determined by Bragg's law, $\mathrm{n} \lambda=2 \cdot \mathrm{d} \cdot \sin \theta$. Surface morphology, chemical composition, and particle size were studied by a FEI- TENEO Field Emission Scanning Electron Microscope (FESEM) (FEI-THERMOFISHER, OR, USA) and a JEOL (Akishima, Tokio, Japan) JEM 2100 High Resolution Transmission Electron Microscope (HRTEM) equipped with an X-ray Energy Dispersive (XEDS) detector. For the TEM, representative samples were prepared using a suspension of CZO particles dispersed in acetone by ultrasonic treatment. Afterwards, these suspensions were dropped onto a carbon-coated copper grid and then subsequently dried in air. The distribution and average size of the CZO particles obtained were determined from the FESEM images. Fast Fourier Transformation (FFT) was used to determine the crystalline orientation and identify the phases. Digital Micrograph TM (DM, Gatan Inc. Pleasanton, CA, USA) software was used for processing the HRTEM images. All the samples were characterized by UV-visible Diffuse Reflectance Spectra (DRS) measured in the range of 350-700 $\mathrm{nm}$ using a UV-visible Spectrophotometer (Varian Cary 100 with DRA-CA-30I Diffuse Reflectance Accessory, Perkin-Elmer, Waltham, MA, USA) at RT. Photoluminescence (PL) spectroscopy measurements werealso performed in a confocal microscope (Horiba Jobin Yvon LabRAM HR800, Minami-ku, Kyoto, Japan) operating with a He-Cd laser $(\lambda=325 \mathrm{~nm})$.

\subsection{Photocatalytic Degradation Test}

The photocatalytic behavior of the nanomaterials obtained was evaluated through the removal reaction of methylene blue $(\mathrm{MB})$ as the test contaminant. The CZO NPs $(12.5 \mathrm{mg})$ were suspended in $600 \mathrm{~mL}$ of a standard $\mathrm{MB}$ aqueous solution $(2.5 \mathrm{ppm})$ in a Pyrex glass reactor (Figure 14), and the mixture was then magnetically stirred over $20 \mathrm{~min}$ in the absence of light, to obtain the adsorption equilibrium. The dye concentration was selected according to the current literature and with the aim of optimizing the experimental conditions for $1 \mathrm{~h}$ runs and to have a consistent base for comparison with previous experiments. Concentrations lower than the one selected for the absorbance sensitivity at the final stages of the experiment would be much lower. For higher dye concentrations, it would be in the first stages in which the sensitivity would be much worse. The photocatalytic degradation was carried out over $60 \mathrm{~min}$, with continuous stirring under UV-light irradiation ( $365 \mathrm{~nm}$ ), in a dark room with $125 \mathrm{~W}$ low-pressure mercury vapor lamp (Jinfei Company, Shanghai, China). The UV lamp light flux was $0.62 \mathrm{~W} / \mathrm{cm}^{2}$. Every $10 \mathrm{~min}$, a constant volume of MB solution (an aliquot of $3 \mathrm{~mL}$ ) was taken to evaluate the photocatalytic degradation process by measuring the absorption spectra using a UV-visible spectrophotometer (Lambda 14P, Perkin-Elmer, Waltham, MA, USA). To corroborate that no significant decomposition of MB had been generated in the absence of CZO NPs and UV light, blank experiments were performed at RT under the same conditions of measurement. The photocatalytic activity (PCA) of the CZO samples was also evaluated by comparing the degradation fraction and the apparent reaction rate constants $(k)$ using the following relations:

$$
\begin{gathered}
\text { Degradation }=\left(C_{0}-C\right) / C_{0} \times 100 \% \\
k=(1 / t) \cdot \ln \left(C_{0} / C\right)
\end{gathered}
$$

where $C_{0}$ is the initial $\mathrm{MB}$ solution concentration at adsorption/desorption equilibrium in the dark $(t=0) ; C$ is the MB solution concentration at time $(t)$. 


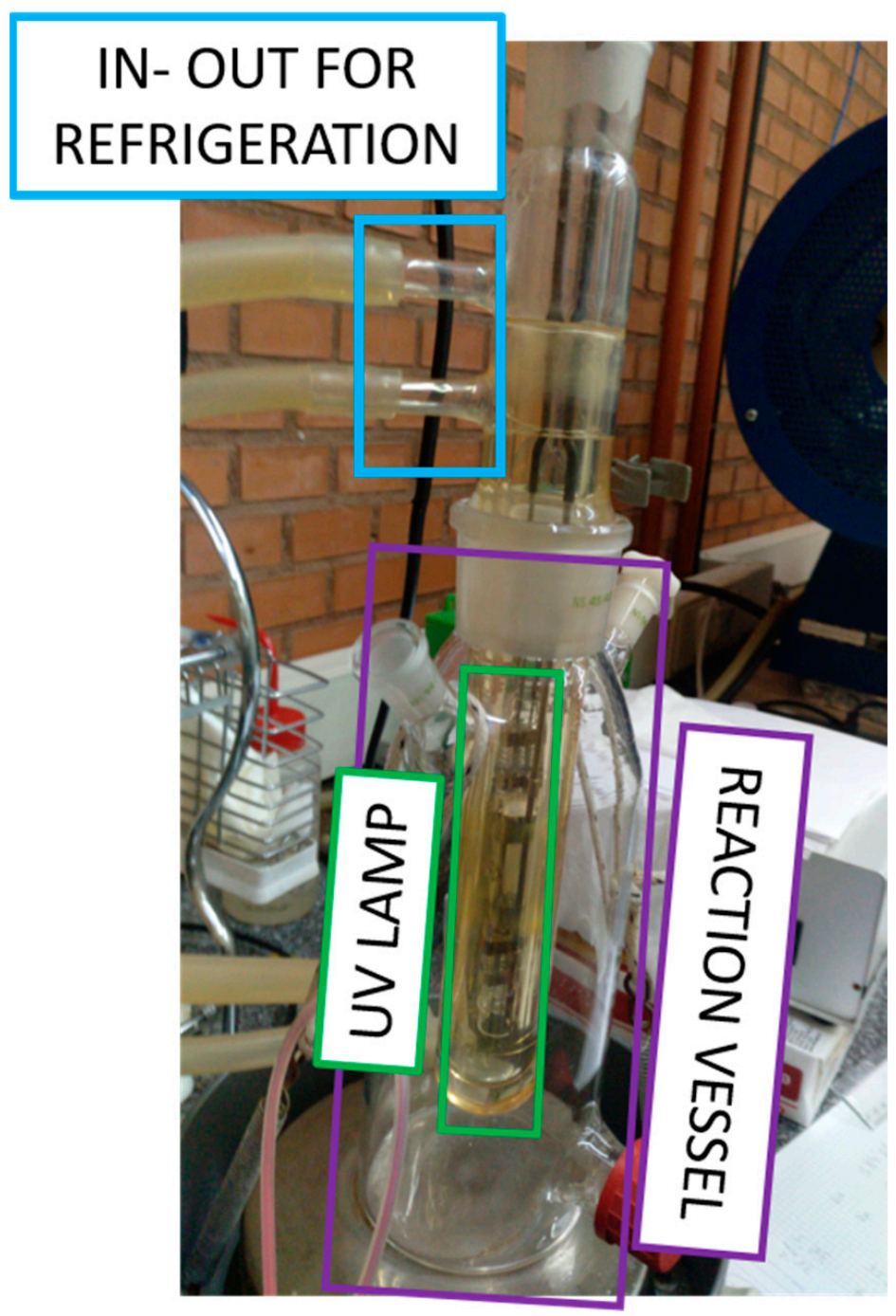

Figure 14. Scheme of the reactor for photocatalysis experiments.

\section{Conclusions}

Pure $\mathrm{ZnO}$ and CZO NPs were successfully synthesized by a simple polyol method, a facile and fast method of one single step. The effects of doping different concentrations of Ce on the microstructure, morphology, and optical properties of ZnO NPs and its PCA for the degradation of $\mathrm{MB}$ were examined. The XRD pattern of the nanomaterials showed that up to $3.24 \%$ successful doping of $\mathrm{Ce}$ in $\mathrm{ZnO}$ was obtained, but a further increase in $\mathrm{Ce}$ at.\% led to a decrease in the crystalline quality. The FESEM and TEM images depicted a transformation from spherical-equiaxial to rice grain shaped particles of the NPs with increased Ceat.\%. PL experiments also showed a decrease in UV emission components in the doped samples as well as changes in the defect structure of $\mathrm{ZnO}$ due to Ce-doping. However, neither significant changes in the bandgap nor in the lattice parameters were observed, suggesting a strong influence of the defects on the lattice relaxation and Ce incorporation. An optimum Ce concentration for the PC process was observed at 3.24 atomic\%. Higher Ce contents would lead to a larger defect concentration and hence a higher electron-hole recombination rate, with subsequent reduction of PC efficiency.

Author Contributions: Validation, Formal Analysis, Investigation, Writing-Original draft preparation, Writing-Review \& Editing, Visualization G.F.-C.; Validation, Formal Analysis, Investigation, M.R.-P.; Conceptualization, Methodology, Validation, Formal Analysis, Investigation, WritingReview and Editing, Visualization, Supervision A.U., P.F., and M.E.R.; Project administration, 
Funding acquisition P.F. and M.E.R. All authors have read and agreed to the published version of the manuscript.

Funding: This research was supported by the projects TecNM (8134.20-PD), CONACYT-México, Comunidad Autónoma de Madrid (CAM-S2018/NMT-4411), MINECO/FEDER-MAT2015-65274-R, MINECO/FEDER-MAT2016-80875-C3-3R and UCM-Santander 2019 (PR87/19-22613).

Informed Consent Statement: Not applicable.

Acknowledgments: This research was supported by the projects TecNM (8134.20-PD), CONACYTMéxico and Comunidad Autónoma de Madrid (CAM-S2018/NMT-4411). Also, the authors are grateful the support via the projects MINECO/FEDER-MAT2015-65274-R, MINECO/FEDER-MAT201680875-C3-3R and UCM-Santander 2019 (PR87/19-22613).

Conflicts of Interest: The authors declare no conflict of interest.

\section{References}

1. Flores, G.; Carrillo, J.; Luna, J.; Martínez-Martínez, R.; Sierra-Fernandez, A.; Milošević, O.; Rabanal, M.E. Synthesis, characterization and photocatalytic properties of nanostructured $\mathrm{ZnO}$ particles obtained by low temperature air-assisted-USP. Adv. Powder Technol. 2014, 25, 1435-1441. [CrossRef]

2. Yoshida, T.; Niimi, S.; Yamamoto, M.; Nomoto, T.; Yagi, S. Effective nitrogen doping into $\mathrm{TiO}_{2}\left(\mathrm{~N}_{-} \mathrm{TiO}_{2}\right)$ for visible light response photocatalysis. J. Colloid Interface Sci. 2015, 447, 278-281. [CrossRef] [PubMed]

3. Muñoz-Fernandez, L.; Sierra-Fernandez, A.; Flores-Carrasco, G.; Milošević, O.; Rabanal, M.E. Solvothermal synthesis of $\mathrm{Ag} / \mathrm{ZnO}$ micro/nanostructures with different precursors for advanced photocatalytic applications. Adv. Powder Technol. 2017, 28, 83-92. [CrossRef]

4. Lopes, O.F.; Paris, E.C.; Ribeiro, C. Synthesis of $\mathrm{Nb}_{2} \mathrm{O}_{5}$ nanoparticles through the oxidant peroxide method applied to organic pollutant photodegradation: A mechanistic study. Appl. Catal. B Environ. 2014, 144, 800-808. [CrossRef]

5. Dirany, N.; Arab, M.; Leroux, C.; Villain, S.; Madigou, V.; Gavarri, J.R. Effect of $\mathrm{WO}_{3}$ Nanoparticles Morphology on the Catalytic Properties. Mater. Today Proc. 2016, 3, 230-234. [CrossRef]

6. Sudrajat, H.; Sujaridworakun, P. Correlation between particle size of $\mathrm{Bi}_{2} \mathrm{O}_{3}$ nanoparticles and their photocatalytic activity for degradation and mineralization of atrazine. J. Mol. Liq. 2017, 242, 433-440. [CrossRef]

7. Flores-Carrasco, G.; Muñoz-Fernandez, L.; Alcántara-Iniesta, S.; Soto-Cruz, B.; Milošević, O.; Rabanal, M.E. Structural and functional properties of $\mathrm{ZnO}$ thin films grown on $\mathrm{Si}$ substrates by air assisted USP method from non-aqueous solutions at low-temperature. Adv. Powder Technol. 2017, 28, 93-100. [CrossRef]

8. Chen, Y.; Zhao, H.; Liu, B.; Yang, H. Charge separation between wurtzite ZnO polar $\left.\begin{array}{llll}0 & 0 & 1\end{array}\right\}$ surfaces and their enhanced photocatalytic activity. Appl. Catal. B Environ. 2015, 163, 189-197. [CrossRef]

9. Yuan, Y.; Huang, G.-F.; Hu, W.-Y.; Xiong, D.-N.; Huang, W.-Q. Tunable synthesis of various ZnO architectural structures with enhanced photocatalytic activities. Mater. Lett. 2016, 175, 68-71. [CrossRef]

10. Ökte, A.N. Characterization and photocatalytic activity of Ln (La, Eu, Gd, Dy and Ho) loaded ZnO nanocatalysts. Appl. Catal. A Gen. 2014, 475, 27-39. [CrossRef]

11. Kaneva, N.; Bojinova, A.; Papazova, K.; Dimitrov, D. Photocatalytic purification of dye contaminated sea water by lanthanide $\left(\mathrm{La}^{3+}, \mathrm{Ce}^{3+}, \mathrm{Eu}^{3+}\right)$ modified ZnO. Catal. Today 2015, 252, 113-119. [CrossRef]

12. Li, C.; Chen, R.; Zhang, X.; Shu, S.; Xiong, J.; Zheng, Y.; Dong, W. Electrospinning of $\mathrm{CeO}_{2}-\mathrm{ZnO}$ composite nanofibers and their photocatalytic property. Mater. Lett. 2011, 65, 1327-1330. [CrossRef]

13. Yayapao, O.; Thongtem, S.; Phuruangrat, A.; Thongtem, T. Sonochemical synthesis, photocatalysis and photonic properties of $3 \%$ Ce-doped ZnO nanoneedles. Ceram. Int. 2013, 39, S563-S568. [CrossRef]

14. Rezaei, M.; Habibi-Yangjeh, A. Microwave-assisted preparation of Ce-doped ZnO nanostructures as an efficient photocatalyst. Mater. Lett. 2013, 110, 53-56. [CrossRef]

15. Ahmad, M.; Ahmed, E.; Zafar, F.; Khalid, N.; Niaz, N.; Hafeez, A.; Ikram, M.; Khan, M.A.; Hong, Z. Enhanced photocatalytic activity of Ce-doped ZnO nanopowders synthesized by combustion method. J. Rare Earths 2015, 33, 255-262. [CrossRef]

16. Rodríguez-Peña, M.; Flores-Carrasco, G.; Urbieta, A.; Rabanal, M.E.; Fernandez, P. Growth and characterisation of ZnO micro/nanostructures doped with cerium for photocatalytic degradation applications. J. Alloys Compd. 2020, 820, 153146. [CrossRef]

17. Pandey, P.; Kurchania, R.; Haque, F.Z. Structural, diffused reflectance and photoluminescence study of cerium doped ZnO nanoparticles synthesized through simple sol-Gel method. Optik 2015, 126, 3310-3315. [CrossRef]

18. Pathak, T.K.; Coetsee-Hugo, E.; Swart, H.; Swart, C.; Kroon, R.E. Preparation and characterization of Ce doped ZnO nanomaterial for photocatalytic and biological applications. Mater. Sci. Eng. B 2020, 261, 114780. [CrossRef]

19. Chelouche, A.; Touam, T.; Tazerout, M.; Boudjouan, F.; Djouadi, D.; Doghmane, A. Low cerium doping investigation on structural and photoluminescence properties of sol-gel $\mathrm{ZnO}$ thin films. J. Lumin 2017, 181, 448-454. [CrossRef]

20. Chen, Z.-W.; Yao, C.-B.; Han, Y.; Bao, S.-B.; Jiang, G.-Q.; Cai, Y. Synthesis, structure and femtosecond nonlinear absorption properties of Ce-ZnO films. Appl. Surf. Sci. 2020, 502, 144133. [CrossRef] 
21. Sukriti; Chand, P.; Singh, V.; Kumar, D. Rapid visible light-driven photocatalytic degradation using Ce-doped ZnO nanocatalysts. Vacuum 2020, 178, 109364. [CrossRef]

22. Sa-Nguanprang, S.; Phuruangrat, A.; Karthik, K.; Thongtem, S.; Thongtem, T. Tartaric acid-assisted precipitation of visible light-driven Ce-doped $\mathrm{ZnO}$ nanoparticles used for photodegradation of methylene blue. J. Aust. Ceram. Soc. 2020, 56, 1029-1041. [CrossRef]

23. Kardeş, M.; Dindaş, G.B.; Yatmaz, H.C.; Dizge, N.; Öztürk, K. CBD grown pure and Ce-doped ZnO nanorods: Comparison of their photocatalytic degrading efficiencies on AR88 azo dye under visible light irradiation. Colloids Surf. A 2020, 607, 125451. [CrossRef]

24. Wang, Y.N.; Li, J.; Wang, Q. The performance of daylight photocatalytic activity towards degradation of MB by the flower-like and approximate flower-like complexes of graphene with ZnO and Cerium doped ZnO. Optik 2020, 204, 164131. [CrossRef]

25. Chieng, B.W.; Loo, Y.Y. Synthesis of ZnO nanoparticles by modified polyol method. Mater. Lett. 2012, 73, 78-82. [CrossRef]

26. Mezni, A.; Mlayah, A.; Serin, V.; Smiri, L.S. Synthesis of hybrid Au-ZnO nanoparticles using a one pot polyol process. Mater. Chem. Phys. 2014, 147, 496-503. [CrossRef]

27. Cerrato, E.; Gionco, C.; Paganini, M.C.; Giamello, E.; Albanese, E.; Pacchioni, G. Origin of Visible Light Photoactivity of the $\mathrm{CeO}_{2} / \mathrm{ZnO}$ Heterojunction. ACS Appl. Energy Mater. 2018, 1, 4247-4260. [CrossRef]

28. Cerrato, E.; Gionco, C.; Paganini, M.C.; Giamello, E. Photoactivity properties of ZnO doped with cerium ions: An EPR study. J. Phys. Condens. Matter 2017, 29, 444001. [CrossRef]

29. Özgür, Ü.; Alivov, Y.I.; Liu, C.; Teke, A.; Reshchikov, M.A.; Doğan, S.; Avrutin, V.; Cho, S.J.; Morkoç, H. A comprehensive review of ZnO materials and devices. J. Appl. Phys. 2005, 98, 041301. [CrossRef]

30. Lang, J.; Wang, J.; Zhang, Q.; Li, X.; Han, Q.; Wei, M.; Sui, Y.; Wang, D.; Yang, J. Chemical precipitation synthesis and significant enhancement in photocatalytic activity of Ce-Doped ZnO nanoparticles. Ceram. Int. 2016, 42, 14175-14181. [CrossRef]

31. Kohan, A.F.; Ceder, G.; Morgan, D.; Van De Walle, C.G. First-principles study of native point defects in ZnO. Phys. Rev. B 2000, 61, 15019-15027. [CrossRef]

32. Vanheusden, K.; Seager, C.H.; Warren, W.L.; Tallant, D.R.; Voigt, J.A. Correlation between photoluminescence and oxygen vacancies in ZnO phosphors. Appl. Phys. Lett. 1996, 68, 403-405. [CrossRef]

33. Tatsumi, T.; Fujita, M.; Kawamoto, N.; Sasajima, M.; Horikoshi, Y. Intrinsic Defects in ZnO Films Grown by Molecular Beam Epitaxy. Jpn. J. Appl. Phys. 2004, 43, 2602-2606. [CrossRef]

34. Vempati, S.; Mitra, J.; Dawson, P. One-step synthesis of ZnO nanosheets: A blue-white fluorophore. Nanoscale Res. Lett. 2012, 7, 470. [CrossRef]

35. Rezaei, M.; Habibi-Yangjeh, A. Simple and large scale refluxing method for preparation of Ce-doped ZnO nanostructures as highly efficient photocatalyst. Appl. Surf. Sci. 2013, 265, 591-596. [CrossRef]

36. Bazta, O.; Urbieta, A.; Trasobares, S.; Piqueras, J.; Fernández, P.; Addou, M.; Calvino, J.J.; Hungría, A.B. In-Depth Structural and Optical Analysis of Ce-modified ZnO Nanopowders with Enhanced Photocatalytic Activity Prepared by Microwave-Assisted Hydrothermal Method. Catalysts 2020, 10, 551. [CrossRef]

37. Wang, L.; Ji, Z.; Lin, J.; Li, P. Preparation and optical and photocatalytic properties of Ce-doped ZnO microstructures by simple solution method. Mater. Sci. Semicond. Process. 2017, 71, 401-408. [CrossRef]

38. Elias, M.; Amin, K.; Firoz, S.H.; Hossain, A.; Akter, S.; Hossain, A.; Uddin, N.; Siddiquey, I.A. Microwave-assisted synthesis of Ce-doped ZnO/CNT composite with enhanced photo-catalytic activity. Ceram. Int. 2017, 43, 84-91. [CrossRef] 